\title{
Post Operative Pain Control in Inguinal Hernia Repair: Comparison of Tramadol Versus Bupivacaine in Local Wound Infiltration: A Randomized Controlled Trial
}

\author{
E Niyirera ${ }^{1}$, A Kiswezi ${ }^{2,3}$, F Ntirenganya ${ }^{2,4}$ \\ ${ }^{1}$ Ruhengeri Referral Hospital,Rwanda \\ ${ }^{2}$ Department of Surgery, School of Medicine and Pharmacy, College of \\ Medicine and Health Sciences, University of Rwanda \\ ${ }^{3}$ University Teaching Hospital of Butare, Rwanda \\ ${ }^{4}$ University Teaching Hospital of Kigali, Rwanda
}

Correspond to: Emails: niyirerae@gmail.com ahmedkiswezi@yahoomail.com;

https://dx.doi.org/10.4314/ecajs.v22i1.11

Background: Post-operative pain control is a key factor in surgery. It greatly increases patient satisfaction, and influences the hospital stay period.

Local wound infiltration has often been used to control postoperative pain following hernia surgery, with the use of the conventional local anesthetics like Lidocaine or Bupivacaine. The use of Tramadol for local wound infiltration is new and not yet practised in Rwanda. The aim of this study was to compare the postoperative pain control effects and cost effectiveness of Tramadol versus Bupivaaine in wound infiltration following inguinal hernia repair.

Methods: This was a randomized controlled trial conducted between September 2015 and February 2016. Randomization was done using a sealed envelope containing the name of drug to be used for local wound infiltrations following inguinal hernia repair.

Results: A total of 52 patients were enrolled equally in the two study groups. Only one female patient enrolled in the study. Tramadol was found to be superior to Bupivacaine in providing postoperative pain control. $(P=0.000)$. Pain free period was $4.7 \pm 1.3$ hours in Bupivacaine group while it twas more than 12 hours in Tramadol group. Additional analgesia request in both groups was significantly different, in favor of Tramadol. $(P=0.000)$. No complications reported in both groups. Bupivacaine was found to be 5 times more expensive than Tramadol.

Conclusion: Wound infiltration with Tramadol after open inguinal hernia repair offers a superior and prolonged pain control compared to Bupivacaine. The need of additional analgesics is very low after Tramadol wound infiltration compared to Bupivacaine used in the same conditions. In addition, Tramadol is cheaper making its use cost affordable

Key words: Postoperative pain, Wound infiltration, Tramadol, Bupivacaine/ macaine.

\section{Introduction}

Maximizing Postoperative pain control in inguinal hernia repair is essential, in order to facilitate earlier patient discharge from hospital. Inadequate analgesia during the 
postoperative period may have short or long term consequences ${ }^{1}$. Benefits from local infiltration in the wound before closing the skin post hernia repair with Bupivacaine have been proved to be efficient in order to decrease opioids demands subcutaneously, intramuscularly or via intravenously ${ }^{2,3}$.

The local anesthetic effects of opioids have been demonstrated both in clinical and animal models ${ }^{3}$. Even if Tramadol is a weak opioid, it has proved to be effective in pain control if used as local infiltration in the surgical wound before closing the skin ${ }^{5}$. It has a selective anesthetic effect on $\mathrm{N}$ receptors of peripheric nerves ${ }^{3,5}$. Studies have shown that it has a longer postoperative pain control effect and less side effects compared to Bupivacaine when used as local wound infiltration $3,6,7,8$.

Hernia repairs are among the commonest operations carried out by in general surgeons in Rwanda. Currently, the patients are hospitalized for 2-3 days postoperatively; it is believed that inadequate pain control is a contributing factor for the prolonged hospital stay. By maximizing postoperative pain control, inguinal hernia repair can be done as a day case.

\section{Patients and Methods}

This randomized controlled trial was conducted between September 2015 and February 2016. All patients who met the inclusion criteria (adult patients on appointment for elective inguinal hernia repair) and accepted to participate in the study were enrolled. Randomization was done using sealed envelopes containing the name of drug was to be used for infiltration (Tramadol or Bupivacaine). Both the patient and the researcher were blinded. Only the anesthesiologist knew the drug given as he/ she was the one to prepare it and to hand it to the surgeon, ready for infiltration.

The study was conducted in two Rwandan referral hospitals. The University teaching hospital of Butare (CHUB) in Southern province, a public referral hospital with 4 running theaters used for both elective and emergency surgeries in general surgery, orthopedics, ENT and gynecology. It has 509 beds, the surgical department occupying $26 \%$ of them. The second hospital was Rwanda military Hospital (RMH), a referral hospital located in Kigali city; it has 4 theater rooms, used for orthopedics, general surgery, gynecology, plastic surgery, urology and ENT. It currently treats $80 \%$ civilian and $20 \%$ military patients. It offers secondary and tertiary level health care services but its new strategic direction focuses on referral and teaching activities. Adult patients confirmed to have inguinal hernia that needed elective surgery (herniorrhaphy or hernioplasty) and accepted to consent for the study, were enrolled.

In the previous almost similar study ${ }^{7}$, the proportion of those who had not experienced pain necessitating analgesia in group $A$ which had received Tramadol local wound infiltration post herniorrhaphy was $4 / 30$ while in the group $B$ which received Bupivacaine as local wound infiltration were $0 / 30$. In this study, the sample size was calculated to be 50 . But it was further increased by $5 \%$ to account for anticipated contingencies such as non-response or recording error; so it included 52 participants with 26 in each group. Randomization was 


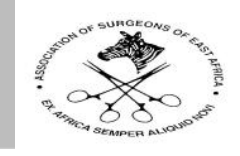

done using a sealed envelope containing the kind of drug, prepared by the researcher then given to the surgeon.

\section{Data analysis}

Analyzed variables included age, ASA classification, types of inguinal hernia, pain free period, pain severity, drug cost, and complications. The data were entered and analyzed using SPSS 16.0 Numerical variables were presented as means plus standard deviations and student " $\mathrm{t}$ " test was used to compare the means between two groups. All the data were calculated on $95 \%$ confidence interval. A $P$ value $<0.05$ was considered as statistically significant level for all comparisons

\section{Results}

The study was carried out from September 2015 till February 2016. It included 51 males and one female. Their ages were ranging between 16 years and 85 years. The mean age was $43.5 \pm 20.5$ years in the group received Bupivacaine (group B); and $41 \pm 18$ years in group which received Tramadol (group $\mathrm{T}$ ). Both groups were comparable with respect to age. The study patients were mainly male (51/52), despite cumulative enrollment. This was probably due to the fact that inguinal hernias are more common in men. The inguinal hernias in this study were indirect (43 or $82 \%$ ), while 9 or $18 \%$ were direct. Most of the patients in this study were in the ASA1 category (88\%), while the rest were in ASA2 category. Generally, no drug side effects were observed in during this study.

We didn't calculate the mean of starting requesting adjuvant analgesia in the group with Tramadol as there was single patient who received adjuvant analgesia in that group in the study period.

Table 2. Pain severity in 2 groups at every Visit (V)

\begin{tabular}{|l|l|c|c|c|c|c|c|c|}
\hline & & V0 & V1 & V2 & V3 & V4 & V5 & V6 \\
\hline Bupivacaine & No pain & 26 & 12 & 7 & 2 & 2 & 1 & \\
\cline { 2 - 11 } & Mild & & 14 & 14 & 10 & 3 & 0 & \\
\hline & Moderate & & & 3 & 6 & 3 & 1 & \\
\hline & Severe & & & 2 & 3 & 6 & 1 & \\
\hline & Total & 26 & 26 & 26 & $\mathbf{2 1}$ & $\mathbf{1 2}$ & $\mathbf{3}$ & $\mathbf{1}$ \\
\hline Tramadol & No & 23 & 22 & 23 & 22 & 22 & 24 & 24 \\
\hline & Mild & 3 & 4 & 2 & 3 & 3 & 1 & 1 \\
\hline & Moderate & & & & & & & \\
\hline & Severe & & & 1 & & & & \\
\hline
\end{tabular}



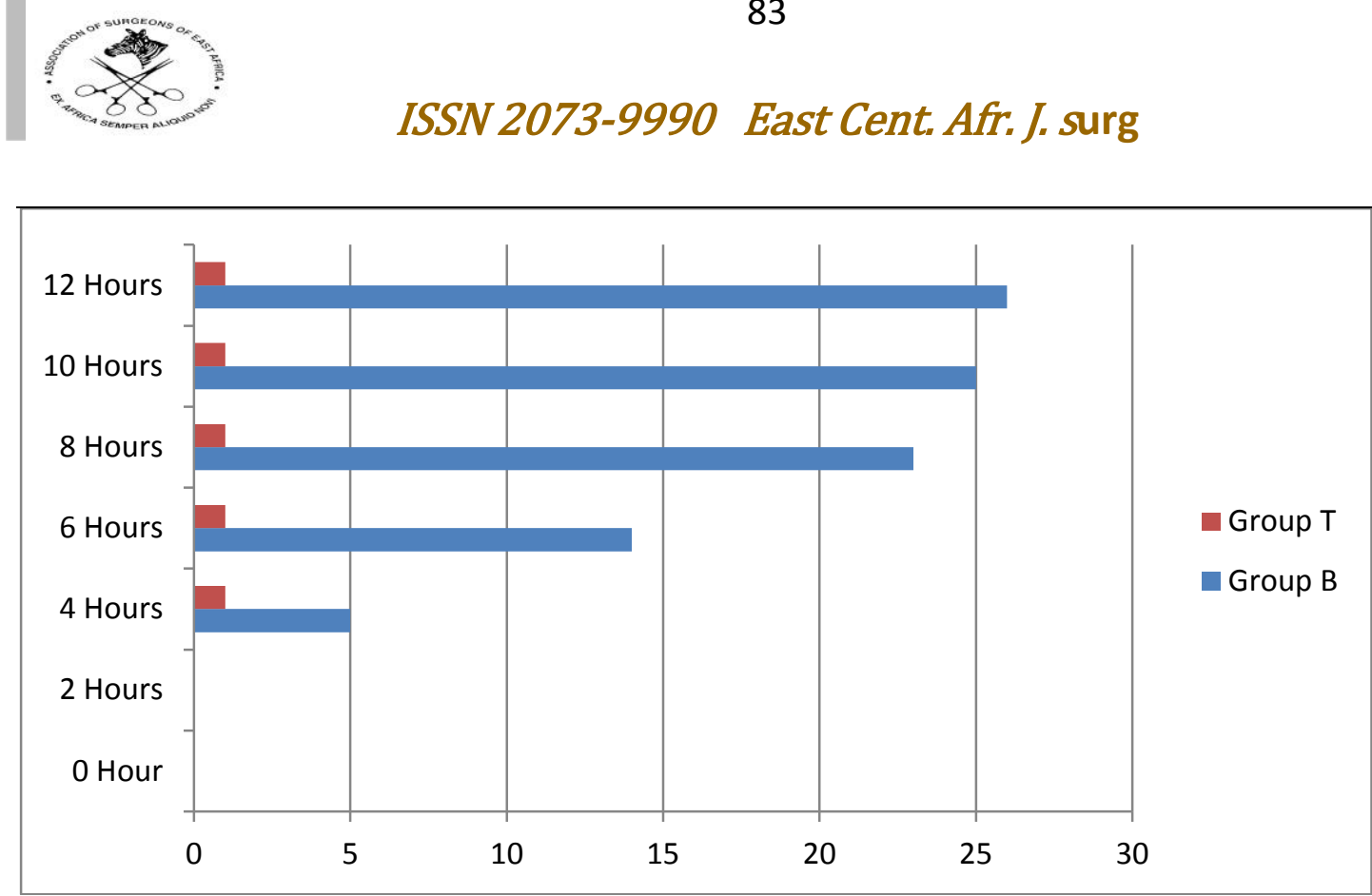

Figure 1. Adjuvant analgesia demand in both Groups

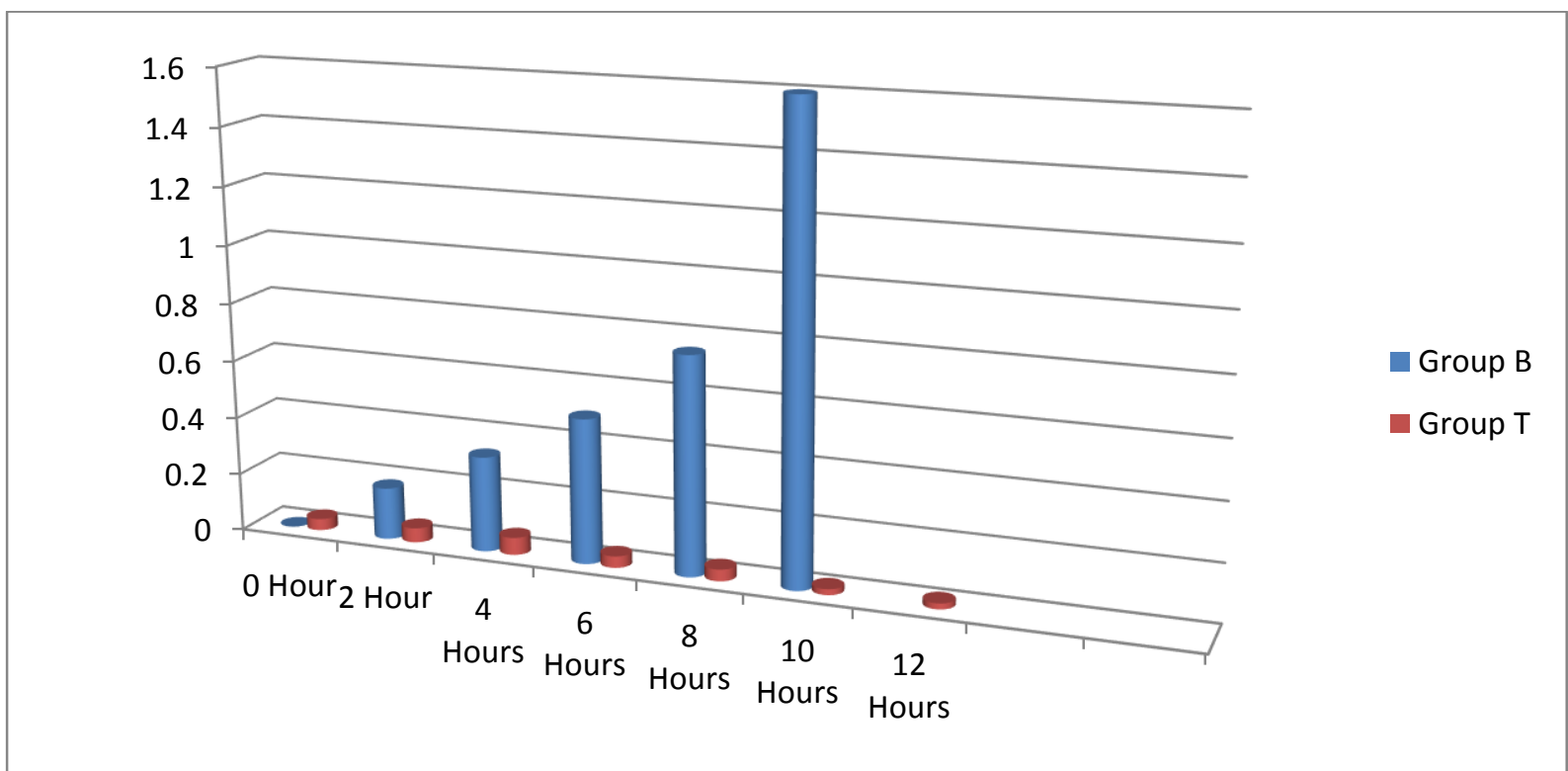

Figure 2. Post Hernia VDS Pain Score Mean After Every Two Hours in Each Group

Figure 2 shows how the pain was fluctuating in both groups. In the group which received Bupivacaine the pain was significantly increasing with time while in the group which received Tramadol the pain was not significant and was decreasing with time.

The sig (2-tailed) value is 0.000 . This value is less than 0.05 . Because of this, we concluded that there is a statistically significant difference between the mean of patients who received Tramadol and the mean of patients who received Bupivacaine in rescuing adjuvant analgesia. Since our group Statistics box revealed that the mean of tolerable pain in group received Tramadol was greater than the mean for tolerable pain the group which received Bupivacaine. 


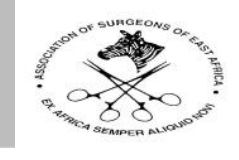

Table 3. Comparison of Means of Time to Rescue the First Analgesia

\begin{tabular}{|c|c|c|c|c|c|c|c|c|c|c|}
\hline \multicolumn{11}{|c|}{ Independent Samples Test } \\
\hline & & \multicolumn{2}{|c|}{$\begin{array}{l}\text { Levene's } \\
\text { Test for } \\
\text { Equality } \\
\text { of } \\
\text { Variance } \\
\text { s }\end{array}$} & \multicolumn{7}{|c|}{ t-test for Equality of Means } \\
\hline & & \multirow[t]{2}{*}{$\mathrm{F}$} & \multirow[t]{2}{*}{ Sig } & \multirow[t]{2}{*}{$\mathrm{t}$} & \multirow[t]{2}{*}{$d f$} & \multirow[t]{2}{*}{$\begin{array}{l}\text { Sig. (2- } \\
\text { tailed) }\end{array}$} & \multirow[t]{2}{*}{$\begin{array}{l}\text { Mean } \\
\text { Differe } \\
\text { nce }\end{array}$} & \multirow[t]{2}{*}{$\begin{array}{l}\text { Std. } \\
\text { Error } \\
\text { Differe } \\
\text { nce }\end{array}$} & \multicolumn{2}{|c|}{$\begin{array}{l}\text { 95\% Confidence } \\
\text { Interval of the } \\
\text { Difference } \\
\text { Lower }\end{array}$} \\
\hline & & & & & & & & & Lower & Upper \\
\hline \multirow{2}{*}{$\begin{array}{l}\text { Start } \\
\text { request } \\
\text { ing } \\
\text { analgesi } \\
\text { cs }\end{array}$} & $\begin{array}{l}\text { Equal } \\
\text { variances } \\
\text { assumed }\end{array}$ & $\begin{array}{r}1.0 \\
32\end{array}$ & $\begin{array}{r}.3 \\
15\end{array}$ & $\begin{array}{r}16.2 \\
62\end{array}$ & 50 & .000 & 6.885 & .423 & 6.034 & .7735 \\
\hline & $\begin{array}{l}\text { Equal } \\
\text { variances } \\
\text { not } \\
\text { assumed }\end{array}$ & & & $\begin{array}{r}16.2 \\
62\end{array}$ & $\begin{array}{r}44.8 \\
99\end{array}$ & .000 & 6.885 & .423 & 6.032 & .7737 \\
\hline
\end{tabular}

\section{Cost of the Drugs}

In the hospital pharmacy, we found that the cost of Tramadol $100 \mathrm{mg}$ was 400 Rwanda francs (0.52USD) whereas the cost of Bupivacaine $0.5 \% 20 \mathrm{ml}$ was 4300 Rwandan francs (5.6USD), Diclofenac IM vial of 75mg was 100 Rwandan Francs (0.13 USD) whereas the price of Paracetamol tablets of 500mg was 100 Rwandan francs (0.13USD), 10 tablets.

This means that the patients in the group received Tramadol with local wound infiltration paid 400 Rwandan francs (0.52USD) in 12 hours for pain medications, for each patient, whereas the patients in the group received Bupivacaine the one who received Bupivacaine and Diclofenac IM paid 4400 Rwandan francs (5.73USD), the same as the one who received Paracetamol tablets.

\section{Discussion}

Given an increasing trend of day case surgery and early hospital discharge, role of pain relief via local wound infiltration is increasingly becoming common ${ }^{1,2,11}$. In this study, local wound infiltration with Tramadol before closing the skin after inguinal hernia repair, provided a significant postoperative pain relief when compared to Bupivacaine ( onset of postoperative pain requiring adjuvant analgesics was more than 12 hours vs $4.7 \pm 1.23$ hours for Tramadol and Bupivacaine respectively) ( $P=0.000$ ). Afaq Iqbal Malik et al found that when Tramadol used locally post inguinal hernia repair, at $2 \mathrm{mg} / \mathrm{kg}$ body weight the mean time for requiring adjuvant analgesic was 11.6 hours, while when Bupivacaine used as local wound infiltration at $0.25 \% 10 \mathrm{cc}$ the mean time for requiring adjuvant analgesics was 8.2 hours ${ }^{6}$. 
Furthermore, the study done by Abdullah M Kaki et al from the Department of Anaesthesia, Faculty of Medicine, King Abdalaziz University Hospital, Jeddah, Saudi Arabia in 2008, found that Tramadol used locally at $1 \mathrm{mg} / \mathrm{kg}$ total body weight diluted in normal saline post inguinal hernia repair, the first adjuvant analgesia requirement was $6.6 \pm 0.99$ hours, while in the group which received Marcaine $0.25 \% 10 \mathrm{cc}$ the mean time to rescue the first adjuvant analgesia was $3.7 \pm 0.74$ hours $^{7}$. Demiraran et al. also made a study comparing post hernia local wound infiltration with Tramadol and Bupivacaine and showed that the pain score was high in the group received Bupivacaine than in the group received Tramadol $(P<0.005)$, Average time to first analgesic requirement was significantly longer in group $T(6.72 \pm 4.09 \mathrm{~h}$ after herniotomy than both group I $(4.49+/-3.9 h)$ and group $B(6.04 \pm 3.7 h)(P<0.05)^{23}$

Hernia repair with either tension free (Lichtenstein procedure) or herniorrhaphy (using modified Bassini technique) were used equally. The choice of the technique was based on surgeon's preference but also on the availability of prolene mesh. It may be thought that the variety of surgical techniques could have caused bias and influence regarding postoperative pain. However, the analysis did not shown any difference. Operators were either consultant general surgeons or senior residents in general surgery. This constitutes one of our study limitations as multiple operators with different level of expertise have been involved.

The severity of self reported pain was high in the group which received Bupivacaine compared to the group which received Tramadol $(P=0.000)$ (Figure 2). In the study done by Abdllah M. Kaki et al there was a significant difference between the two groups in the recorded visual analog pain scale rating high in group with Bupivacaine $(P<0.05)$. In the study done by Bahanur $C$. et al revealed that the severity of pain was high in the group which received L Bupivacaine compared to the group which received Tramadol ${ }^{8}$.

Side effects also have been evaluated in our study; we evaluated nausea, vomiting, bradycardia and hypotension, no single side effect recorded in the 2 groups. Bahnur $\mathrm{C}$ et al, in their study comparing Tramadol and Bupivacaine used as local wound infiltration they were monitoring side effects of each drug( nausea, vomiting, cardiovascular), no side effect found in their study ${ }^{8}$.

In the study done by M.E. Ausems et al, evaluating side effects of Bupivacaine used locally there were no side effect related to the local wound infiltration with Bupivacaine ${ }^{[24]}$.

In this study the cost of all products the patients consumed along our study period has been evaluated, we found that the group received Tramadol paid 10 times low for analgesia as one vial of Tramadol was 0.52USD, whereas the group received Bupivacaine one vial $20 \mathrm{ml}$ was 5.6 USD plus additional analgesics received to control pain better.

\section{Conclusion}

Wound infiltration with Tramadol after open inguinal hernia repair offers a superior and prolonged pain control compared to Bupivacaine. The need of additional analgesics is very 


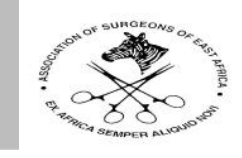

low after Tramadol wound infiltration compared to Bupivacaine used in the same conditions. In addition, Tramadol is cheaper making its use cost affordable

\section{Referencs}

1. Srinivas Pyati, Tong J. Gan. Perioperative pain management. CNS drugs 2007; 21(3): 185- 221

2. Slavica K, Jozo K, Kata, S et al A wound infiltration as a method of postoperative analgesia. Periodicum biologorum 2009:111(2): 241- 246

3. Seyed S. R, Hasan P, Ali Reza B.J, et al. Magnesium versus Bupivacaine infiltration in controlling postoperative pain in inguinal hernia repair. Anesth Pain Med 2015; 5(6): 306-43

4. Gamal M, Ahmed A, B. Ahmed El- sakka, Amr W. Does tramadol or bupivacaine intraincisional infiltration with inguinal canal block during hernioplasty changes the postoperative pain profile?Ain- Shams Journal of Anesthesiology 2015; 08: 107-113

5. Rehan Muhammad Qureshi, Fauzia Anis Khan. Effects of bupivacaine infiltration on postoperative tramadol consumption in elective day care unilateral inguinal hernia repair. J Pak Med Ass 2016; 66(3)

6. Stein C, Gramsch C, Hern A. Intrinsic mechanisms of antinociception in inflammation: local opioid receptors and beta endorphins. J Neurosci 1990; 10:12928.

7. Afaq Iqbal Malik, Irfan Ali Sheikh, Shahzad Ahmed Qasmi, Ahmed Adnan. Comparison of Tramadol with Bupivacaine as Local Anaesthetic in Postoperative Pain Control. Journal of surgery Pakistan 2011; 16:1.

8. Abdullah M kaki, Waleed Al Marakbi. Post- herniorrhaphy infiltration of tramadol versus bupivacaine for postoperative pain relief: a randomized study. Ann Saudi Med 2008; 28(3):165-168.

9. Bahanur C, Ufuk D, Sukran G, Engin E. Comparison of postoperative Analgesic effects of wound infiltration with tramadol versus Levobupivacaine in children undergoing inguinal hernia and undescended testis surgery. Eur J. Gen Med 2013; 10(2):74-78.

10. Gregory J, Richardson C. The use of Pain assessment tools in clinical practice: a pilot survey. J Pain relief 2014;3:2

11. Justin P W, Charles F.B, Parviz K. 2015. Inguinal hernia.In Dana K. Anderson ed. Schwartz Principle of surgery Mc Graw- Hill pp 1498- 1551

12. H.R. Langeveld- Benders, 2014. Inguinal hernia surgery: A patient centered approach. Rotterdam Erasmus University.

13. Farzaneh E, Navid N, Mohammed F, Meysan M. Analgesic effect of Naproxen suppository and local marcaine injection on inguinal hernia surgery. Arch crit care Med 2015;1(1) e521

14. Timothy J. Brennan. Pathophysiology of Postoperative pain. Pain 2011;152(3): 533540

15. David Wels. Management of postoperative pain.Anaesthesia supplement 2012; $54: 3$

16. Manimala Rao. Acute postoperative pain. Anaesthesia;2006 50(5):340-344

17. Philip Coke. Postoperative pain management. 2013: 36(6): 202-2058 
18. Volkan H, Sedat H, Haktan O, et al. Comparison of the effects of Bupivacaine, lidocaine and tramadol infiltration on wound healing in rats. Rev Bras anestesiol 2012; 62(6):799-810.

19. Guillome C S, Gisela M B, Fabio L Q et al. Assessment of postoperative pain and hospital discharge after inguinal and iliohypogastic nerve block for inguinal hernia repair under spine anesthesia: a prospective study. Rev Assoc Med Bras 2011; 57(5):535-538.

20. Joshi G.P, Rawal N, Kehlet $H$ et al. 2011. Evidence -based management of postoperative pain in adults undergoing open inguinal hernia surgery. British journal of surgery. BJS

21. Rose M, Judith I, Julia A. Infiltration of local anesthetics for postoperative analgesia. http: //www.pfiedlerentreprises.com/ pdf. Accessed March 2016.

22. Tanay N. Shah, Pratham R. Byasani, Nikhil Sharma. Effect of intraoperative bupivacaine infiltration for postoperative pain relief in open inguinal hernia repair. IJSR, India ISSN: 2319-7064.

23. Justin P W, Charles F.B, Parviz K. 2015. Inguinal hernia. In Dana K. Anderson ed. Schwartz Principle of surgery Mc Graw- Hill pp 1498- 1951

24. . Demiraran Y, Ilce Z, Kocaman B, Bozkurt P. Does tramadol wound infiltration offer an advantage over bupivacaine for postoperative analgesia in children following herniotomy? Paediatr Anaesth. 2006 Oct; 16 (10):1047-50.

25. M.E. Ausems, K.W. Hulsewe et al. Postoperative analgesia requirements at home after inguinal hernia repair: effect of wound infiltration on postoperative pain. Anesthesia2007; 62: 325- 331

26. Katherine R. Jones, Carol P. Vojir, Evelyn Hutt, Regina Fink. Determining mild, moderate, and severe pain equivalency across pain intensity tools in nursing home residents. 2007;44(2): 305-314 